\title{
Evaluation of the Efficacy of the Hospital Glycemic Management System for Patients with Malignant Tumors and Hyperglycemia
}

\author{
Juan Jiang* \\ Danlan $\mathrm{Pu}^{*}$ \\ Renzhi Hu \\ Mingyang $\mathrm{Hu}$ (D) \\ Qinan Wu
}

Department of Endocrinology and Nephrology, Chongqing University Cancer Hospital, School of Medicine, Chongqing University, Chongqing, 400030, People's Republic of China

*These authors contributed equally to this work
Correspondence: Qinan Wu Department of Endocrinology and Nephrology, Chongqing University Cancer Hospital, School of Medicine, Chongqing University, Chongqing, People's Republic of China EmailwqnII@I26.com
Objective: To explore the efficacy of the hospital glycemic management system with information integration in patients with malignant tumors and hyperglycemia.

Methods: Three hundred ninety-three patients diagnosed with malignant tumors with hyperglycemia and hospitalized in the non-endocrinology department of a specialized cancer hospital from March 2019 to November 2020 were recruited. All the patients were diagnosed and treated according to the clinical department and disease course. In total, 196 patients were divided into the control group, who received the conventional blood glucose management mode, and 197 patients were divided into the intervention group, who received the hospital glycemic management system with information integration. The average daily glucose levels were recorded before and after breakfast, lunch, and dinner, at bedtime and at night. The average glucose level, glucose compliance rate, hypoglycemia rate, hyperglycemia rate, glucose measurements per day, average number of hospitalization days and patient satisfaction were compared between the groups.

Results: In the intervention group, the average glucose level was significantly lower than that in the control group $(\mathrm{P}<0.05)$. The hyperglycemia and hypoglycemia rates in the intervention group were lower than those in the control group $(\mathrm{P}<0.05)$. The glucose compliance rate in the intervention group was higher than that in the control group $(\mathrm{P}<0.05)$. The highest blood glucose level in the intervention group was lower than that in the control group $(\mathrm{P}<0.05)$, and the lowest blood glucose level was higher than the control group $(\mathrm{P}<0.05)$. The glucose measurements per day in the intervention group were higher than those in the control group, and the average number of hospitalization days in the intervention group was lower than that in the control group $(\mathrm{P}<0.05)$. Patient satisfaction in the intervention group was higher than that in the control group $(\mathrm{P}<0.05)$.

Conclusion: The hospital glycemic management system with information integration significantly improved the glycemic management of patients with malignant non-endocrine tumors and hyperglycemia, including their glucose level and glucose compliance rate, as well as patient satisfaction, and reduced the average number of hospitalization days and risk of hyperglycemia/hypoglycemia.

Keywords: information integration, malignant tumor with hyperglycemia, hospital glycemic management system

\section{Introduction}

With the increasingly westernized lifestyle, malignant tumors and diabetes have increased and have become two major diseases that seriously threaten human health. ${ }^{1}$ According to the International Diabetes Federation (IDF), 425 million 
adults have diabetes worldwide, and 121 million live in China. ${ }^{2}$ Researchers have suggested that diabetes is closely related to the occurrence, development and death of various malignant tumors, such as pancreatic cancer, colorectal cancer, gastric cancer, liver cancer, and breast cancer. $^{3-9}$ When the tumor is complicated by hyperglycemia, glycemic management becomes more complicated because of the specificity and treatment of the tumor. The rate of glycemic control is lower, and the prognosis is generally poor. ${ }^{10-12}$ Approximately $30.4 \%$ of malignant tumor patients after chemotherapy have blood glucose levels higher than $16.7 \mathrm{mmol} / \mathrm{L}$, and they may even develop ketoacidosis and hyperosmolar coma. ${ }^{13}$ The interaction between hyperglycemia and tumors is an important factor affecting the safety, effectiveness and prognosis of patients. The survey also indicated that most cancer patients with hyperglycemia are scattered among various non-endocrinology departments, and glycemic management is a problem. Presently, for cancer patients with hyperglycemia, the frequency of glycemic monitoring is insufficient, hyperglycemic and hypoglycemic events are common, and the blood glucose compliance rate is low (It is suggested that $\mathrm{HbAlc}$ control target value of nonpregnant adult diabetes patients should be less than $7.0 \%$, the pre-meal blood glucose should be less than 4.4-7.2 $\mathrm{mmol} / \mathrm{l}$, and the peak blood glucose level after a meal should be less than $10.0 \mathrm{mmol} / \mathrm{l}$ in diabetic patients), seriously affecting the treatment effect and safety of patients. ${ }^{12}$ Therefore, it is crucial to perform effective glycemic management of cancer patients with hyperglycemia to improve the quality of the glycemic management of these patients in non-endocrinology departments and to avoid the adverse effects of hyperglycemia and hypoglycemia on the patients' health to the greatest extent possible. Few specialized cancer hospitals in China have established a hospital glycemic management system. Therefore, our study created a hospital glycemic management system with information integration to screen for glycemic control in cancer patients with hyperglycemia to improve the quality of glycemic management in cancer patients with hyperglycemia.

\section{Materials and Methods}

\section{Subjects and Group Classification}

The protocol was approved by the Chongqing University Cancer Hospital, School of Medicine, Chongqing University Institutional Review Board, conformed to the standards of the Declaration of Helsinki and is registered with Clinical Trials.gov (NCT02535299). Two hundred patients who were diagnosed with malignant tumors and hyperglycemia at the non-endocrinology department (16 departments and 27 wards) of our hospital from March 2019 to November 2020 were randomly divided into a control group and an intervention group. The patients in the control group were treated according to the clinical course of the disease, and their blood glucose levels were managed using the conventional blood glucose management mode. During the study, 4 patients were lost to follow-up in the control group, with a loss rate of $2 \%$. Among them, 2 patients left the hospital voluntarily, 1 patient needed to be transferred to the hospital for treatment due to illness, and 1 patient was transferred to the intensive care unit (ICU). Finally, 196 patients were included in the control group, comprising 99 men and 97 women. The patients in the intervention group were also treated according to the clinical course of their disease, and they were enrolled in the hospital glycemic management system with information integration at the same time. In the intervention group, 3 patients were lost to follow-up, and the loss rate was $1.5 \%$. Among them, 1 patient was transferred to another hospital, and 2 patients left the hospital voluntarily. Finally, 197 patients were included in the intervention group, comprising 93 men and 105 women. Method of blood glucose detection: Venous blood was collected at specific times using the glucose oxidase method. The blood glucose meter and testing paper were provided by Roche Diagnostic Products (Shanghai) Co., Ltd.

The inclusion criteria were as follows: (1) patients hospitalized for more than 24 hours and aged between 18 and 70 years; (2) patients with a diagnosis of a malignant tumor with hyperglycemia; ${ }^{14}$ (3) patients with a malignant tumor who have a clinical treatment course; (4) patients willing to provide signed informed consent. The exclusion criteria were as follows: (1) patients with cardiovascular, cerebrovascular, liver, respiratory and renal failure; (2) patients with severe malnutrition (plasma albumin $<25 \mathrm{~g} / \mathrm{L}$ ); (3) pregnant and lactating women; (4) patients with uncontrollable infection;(5) patients with mental and neurological diseases that cannot cooperate or are unwilling to cooperate.

\section{Group and Intervention Control Group}

The traditional blood glucose management mode was adopted. The patients were treated according to the clinical course of the disease. A portable blood glucose meter was 
used for blood glucose monitoring. Nurses recorded the glucose data in the medical record system, and then doctors checked the glucose data of the patients using the medical record system. If hyperglycemia was observed, a comprehensive blood glucose monitoring scheme and hypoglycemic scheme were used. If necessary, an endocrinology doctor was consulted. According to the clinical opinion after consultation, doctors of all the departments were expected to perform hypoglycemic treatment until the target value is reached or the treatment window is closed.

\section{Intervention Group}

This group received the hospital glycemic management system with information integration. (1) Establishment of the information hospital professional glycemic management team: This team included the director of the Endocrinology Department, medical team leader, fulltime glycemic management doctor (chief resident), chief nurse, diabetes specialist nurse, diabetes liaison nurse, and information technology specialist to standardize glycemic of cancer patients with hyperglycemia. (2) Establishment of an Internet-based glucose monitoring system (IBGMS): This system included the hospital information system (HIS), Nova network server, intelligent blood glucose management system and intelligent blood glucose meter. ${ }^{14}$ After blood glucose monitoring, the data were automatically transmitted to the hospital glycemic management system with information integration and shared with HIS. The system can automatically store, file and analyze all uploaded blood glucose data. In the IBGMS system, medical staff can check the glycemic spectrum of patients during hospitalization, set the alarm threshold for hyperglycemia (yellow) (before a meal $\geq 7.8 \mathrm{mmol} / 1$, after a meal $\geq 10.0 \mathrm{mmol} / \mathrm{l}$ ) and set the alarm threshold for hypoglycemia (red) (blood glucose $\leq 3.9 \mathrm{mmol} / \mathrm{l}$ ). When the blood glucose level is lower or higher than the threshold, the IBGMS system interface will automatically sound the alarm. (3) Horizontal glycemic information management process: After admission, the patient's blood glucose was monitored according to the doctor's advice, and the blood glucose data were automatically uploaded to the hospital glycemic management system with information integration. The full-time blood glucose management physicians at the Endocrinology Department are responsible for managing all patients with abnormal glucose data. Clinicians assess the glucose data in the hospital system every day, focusing on patients whose blood glucose levels are more than $7.8 \mathrm{mmol} / \mathrm{L}$ and less than 3.9 $\mathrm{mmol} / \mathrm{L}$. Using the hospital glycemic management system with information integration, they can access further information on the patient's medical history and course of disease, perform risk evaluation on patients, and provide individualized treatment plans, including glycemic monitoring programs, hypoglycemic programs, and diet adjustments to each department doctor. Endocrinologists and oncologists often work in conjunction to treat patients with abnormal glucose in a timely manner. For patients with complicated conditions and extremely abnormal glucose levels, team members conduct bedside consultations and interventions and adjust the glucose management program in real time according to the changes in the glucose data. Nurses who specialize in diabetes care ensure that the contact nurses check the glucose monitoring data of patients every day and perform nursing guidance and health education for patients to ensure that patients' blood glucose is in an ideal state during disease treatment. (4) Quality control of information-based blood glucose specialists: Full-time doctors collect and summarize highrisk diabetes events using information technology, medical team leaders and diabetes specialist nurses summarize high-risk glucose events using the hospital glycemic management system with information integration every month, and the head nurse supervises the data collection. A special quality control meeting is conducted every month, in which the quality control group performs quality control of blood glucose specialty information, evaluates the quality of the hospital glycemic management system with information integration, and conducts continuous quality improvement.

\section{Data Collection and Outcome Measures}

The main objective was to evaluate the application value of the information integrated in a hospital blood glucose management system for cancer patients with hyperglycemia. Hypoglycemic events were defined as any timely data indicating a blood glucose level $\leq 3.9 \mathrm{mmol} / \mathrm{l}$, and hyperglycemia events were defined as any timely data indicating a glucose level $>7.8 \mathrm{mmol} / \mathrm{l}$ and 2 hours postprandial glucose $>10.0 \mathrm{mmol} / \mathrm{l}$. Incidence of hypoglycemia $(\%)=$ Number of hypoglycemia events/number of patients with blood glucose monitoring $\times 100 \%$. Incidence of hyperglycemia $(\%)=$ Number of hyperglycemia events/number of patients with blood glucose monitoring $\times 100 \%$. Blood glucose normalization rate $(\%)=$ Number of patients 
whose blood glucose reached the standard level/number of patients with blood glucose monitoring $\times 100 \%{ }^{15}$

\section{Statistical Analyses}

Statistical analyses were performed using the statistical software SPSS 19.0. $\mathrm{P}<0.05$ indicated statistical significance. The data were expressed as means \pm standard deviation ( $\mathrm{x}$ $\pm \mathrm{s})$. Before statistical analysis, the data were subjected to normal distribution analysis using the KolmogorovSmirnov's test. The differences between groups were tested using $t$ test. Relationships among the parameters were analyzed by simple correlation analyses. The correlation of variables was determined by Pearson's correlation, and multiple linear regression was used to correct the effects of the covariates and test independent factors.

\section{Results}

\section{Baseline Characteristics of the Patients}

No significant differences were found in the general information, age, sex, weight, body mass index (BMI) or treatment regimens between the groups $(\mathrm{P}>0.05)$ (Table 1). No significant differences were found between the two groups regarding the effects of drugs such as glucocorticoids, paclitaxel, cisplatin, and PD1/PDL1 on blood glucose.

\section{Comparison of Glucose Control}

The average glucose levels in the intervention group before and after breakfast, before and after lunch, at bedtime, and at night were lower than that in the control group; the highest glucose level in the intervention group was lower than that in the control group, and the lowest blood glucose level was higher than that in the control group (Table 2). The glucose compliance rate in the intervention group was higher than that in the control group $(\mathrm{P}<0.05)$ (Table 3). Comparison of the high-risk glucose rate indicated that the incidences of hyperglycemia and hypoglycemia in the intervention group were lower than those in the control group; the differences were statistically significant $(\mathrm{P}<0.05)$ (Table 4$)$.

\section{Comparison of the Glucose Measurements per Day and Average Number of Hospitalization Days}

The glucose measurements per day in the intervention group were higher than those in the control group, and the average number of hospitalization days in the intervention group was lower than that in the control group; this difference was statistically significant $(\mathrm{P}<0.05)$ (Table 5).

Table I Baseline Characteristics of the Patients $(\bar{x} \pm s)$

\begin{tabular}{|c|c|c|c|c|c|c|c|c|c|}
\hline \multirow[t]{2}{*}{ Group } & \multicolumn{2}{|c|}{ Sex } & \multirow[t]{2}{*}{ Age } & \multirow{2}{*}{$\begin{array}{c}\text { Weight } \\
\text { (kg) }\end{array}$} & \multirow{2}{*}{$\begin{array}{c}\text { BMI } \\
(\mathrm{kg} / \mathrm{m} 2)\end{array}$} & \multicolumn{2}{|c|}{ Treatment } & \multirow{2}{*}{$\begin{array}{c}\text { Fasting } \\
\text { Glucose } \\
\text { (mmol/L) }\end{array}$} & \multirow{2}{*}{$\begin{array}{l}\text { Random } \\
\text { Glucose } \\
\text { (mmol/L) }\end{array}$} \\
\hline & Male & Female & & & & Drug & Surgery & & \\
\hline Control group $(n=196)$ & 99 & 97 & $64.03 \pm 5.95$ & $63.20 \pm 9.77$ & $23.56 \pm 2.44$ & 84 & 112 & $9.23 \pm 2.15$ & $12.56 \pm 2.95$ \\
\hline Observation group $(n=197)$ & 92 & 105 & $63.45 \pm 4.78$ & $64.6 I \pm 8.68$ & $23.97 \pm 2.49$ & 92 & 105 & $9.38 \pm 2.64$ & $|2.59 \pm 2.7|$ \\
\hline $\mathrm{t} / \chi^{2} / z$ & \multicolumn{2}{|c|}{$0.57 \mathrm{I}$} & 1.073 & -1.587 & -1.638 & \multicolumn{2}{|c|}{0.587} & -0.620 & -0.072 \\
\hline$P$ & \multicolumn{2}{|c|}{0.450} & 0.284 & 0.113 & 0.102 & \multicolumn{2}{|c|}{0.444} & 0.536 & 0.358 \\
\hline
\end{tabular}

Table 2 Comparison of Glucose Levels at Different Time Periods ( $\bar{x} \pm s$ )

\begin{tabular}{|l|c|c|c|c|c|c|c|}
\hline \multirow{2}{*}{ Group } & $\mathbf{n}$ & \multicolumn{2}{|c|}{ Breakfast } & \multicolumn{2}{c|}{ Lunch } & \multicolumn{2}{c|}{ Dinner } \\
\cline { 3 - 8 } & & $\begin{array}{c}\text { Average } \\
\text { Preprandial } \\
\text { Glucose } \\
\text { (mmol/L) }\end{array}$ & $\begin{array}{c}\text { Average } \\
\text { Postprandial } \\
\text { Glucose } \\
(\mathbf{m m o l} / \mathbf{L})\end{array}$ & $\begin{array}{c}\text { Average } \\
\text { Preprandial } \\
\text { Glucose } \\
(\mathbf{m m o l} / \mathbf{L})\end{array}$ & $\begin{array}{c}\text { Average } \\
\text { Postprandial } \\
\text { Glucose } \\
(\mathbf{m m o l} / \mathbf{L})\end{array}$ & $\begin{array}{c}\text { Average } \\
\text { Preprandial } \\
\text { Glucose } \\
(\mathbf{m m o l} / \mathbf{L})\end{array}$ & $\begin{array}{c}\text { Average } \\
\text { Postprandial } \\
\text { Glucose } \\
(\mathbf{m m o l} / \mathbf{L})\end{array}$ \\
\hline Control group & 196 & $9.41 \pm 2.48$ & $12.77 \pm 2.61$ & $10.87 \pm 3.06$ & $12.96 \pm 2.08$ & $10.27 \pm 3.41$ & $12.53 \pm 2.44$ \\
Observation group & 197 & $8.61 \pm 2.17$ & $10.71 \pm 2.20$ & $9.47 \pm 1.99$ & $10.96 \pm 2.52$ & $8.90 \pm 2.25$ & $10.18 \pm 2.57$ \\
$\mathrm{t}$ & & 3.385 & 8.462 & 5.322 & 10.447 & 4.686 & 9.908 \\
$\mathrm{P}$ & & 0.001 & 0.000 & 0.000 & 0.000 & 0.000 & 0.000 \\
\hline
\end{tabular}


Table 3 Comparison of Glucose Level ( $\bar{x} \pm s)$

\begin{tabular}{|l|c|c|c|c|c|c|}
\hline Group & $\mathbf{n}$ & $\begin{array}{c}\text { Average Bedtime } \\
\text { Glucose } \\
\mathbf{( m m o l / L )}\end{array}$ & $\begin{array}{c}\text { Average Night } \\
\text { Glucose } \\
\mathbf{( m m o l / L )}\end{array}$ & $\begin{array}{c}\text { Average } \\
\text { Glucose } \\
\text { (mmol/L) }\end{array}$ & $\begin{array}{c}\text { Average } \\
\text { Hospitalization } \\
\text { Hyperglycemia (\%) }\end{array}$ & $\begin{array}{c}\text { Average } \\
\text { Hospitalization } \\
\text { Hypoglycemia (\%) }\end{array}$ \\
\hline Control group & 196 & $11.82 \pm 2.67$ & $9.56 \pm 1.86$ & $11.28 \pm 1.05$ & $17.93 \pm 5.70$ & $3.97 \pm 1.22$ \\
Observation group & 197 & $10.15 \pm 2.49$ & $8.90 \pm 1.75$ & $9.93 \pm 0.81$ & $16.91 \pm 3.19$ & $4.30 \pm 0.96$ \\
$\mathrm{t}$ & & 6.408 & 3.620 & 14.237 & 2.186 & -2.997 \\
$\mathrm{P}$ & & 0.000 & 0.000 & 0.000 & 0.029 & 0.003 \\
\hline
\end{tabular}

Table 4 Comparison of the Glucose Compliance Rate, Hyperglycemia Rate and Hypoglycemia Rate $(\overline{\mathrm{x}} \pm \mathrm{s})$

\begin{tabular}{|l|c|c|c|c|}
\hline Group & $\mathbf{n}$ & Glucose Compliance Rate (\%) & Hyperglycemia Rate (\%) & Hypoglycemia Rate (\%) \\
\hline Control group & 196 & $29.61 \% \pm 13.01 \%$ & $72.53 \% \pm 13.23 \%$ & $1.53 \% \pm 1.16 \%$ \\
Observation group & 197 & $55.24 \% \pm 15.53 \%$ & $65.74 \% \pm 9.98 \%$ & $0.98 \% \pm 1.11 \%$ \\
t & & -17.730 & 5.751 & 4.750 \\
P & & 0.000 & 0.000 & 0.000 \\
\hline
\end{tabular}

Table 5 Comparison of Glucose Measurements per Day and Average Hospitalization Days ( $\overline{\mathrm{x}} \pm \mathrm{s})$

\begin{tabular}{|l|c|c|c|}
\hline Group & $\mathbf{n}$ & $\begin{array}{c}\text { Glucose } \\
\text { Measurements } \\
\text { per Day }\end{array}$ & $\begin{array}{c}\text { Average } \\
\text { Hospitalization } \\
\text { Days }\end{array}$ \\
\hline Control group & 196 & $35.76 \pm 16.51$ & $12.56 \pm 2.29$ \\
Observation group & 197 & $46.23 \pm 15.77$ & $10.07 \pm 1.93$ \\
t & & -6.43 & 11.652 \\
P & & $<0.001$ & $<0.001$ \\
\hline
\end{tabular}

\section{Relationships Among the Parameters and Regression Analysis}

Correlation analysis suggested that the glucose measurements per day, average number of hospitalization days, average glucose level and glucose compliance rate were closely related. The glucose measurements per day were negatively correlated with the average number of hospitalization days, and the glucose measurements per day were positively correlated with the glucose compliance rate (see Table 6).

Multiple regression analysis showed that the significant variables were the glucose measurements per day, average number of hospitalization days, average glucose level and hypoglycemia rate. According to $\beta$, the glucose measurements per day and average glucose level showed the greatest correlation with the glucose compliance rate. Multiple regression analysis of the average number of hospitalization days indicated that the average glucose level and glucose compliance rate showed the greatest relationship with the average number of hospitalization days (Tables 7 and 8).

\section{Comparison of Patient Satisfaction}

The satisfaction of patients in the intervention group $(97.46 \%)$ was significantly better than that in the control group $(90.31 \%)(\mathrm{P}<0.05)$ (Table 9).

\section{Discussion}

Managing blood glucose levels in patients with malignant tumors is a challenge for hospital glycemic management, and different objectives and methods of glucose control have been explored worldwide. Patients with malignant tumors and hyperglycemia are usually admitted to a non-endocrinology department. Because of the lack of professional experience and knowledge of glucose management and limitations in the efficiency of the traditional consultation system, the glycemic management of malignant tumor inpatients is difficult, and achieving normal glucose levels in these patients is challenging. Hyperglycemia is an independent risk factor leading to a poor prognosis among patients with malignant tumors. The mortality rate of patients with malignant tumors and hyperglycemia is 1.41 times higher than that of nondiabetic patients with malignant tumors, and the prognosis of cancer patients with hyperglycemia is generally poor. ${ }^{16}$ Building a systematic, comprehensive glycemic management system could help address both malignant tumors and glycemic control in these patients, and its success could help the patients effectively reach standard glucose levels, reducing medical costs and improving the glucose compliance rate and quality of life of patients. 
Table 6 Relationships Among Each Parameter

\begin{tabular}{|c|c|c|c|c|c|c|}
\hline Parameters & $\begin{array}{l}\text { Average } \\
\text { Glucose } \\
\text { Monitoring } \\
\text { Frequency }\end{array}$ & $\begin{array}{l}\text { Average } \\
\text { Hospitalization } \\
\text { Days }\end{array}$ & $\begin{array}{l}\text { Average } \\
\text { Glucose } \\
\text { Level }\end{array}$ & $\begin{array}{l}\text { Glucose } \\
\text { Compliance } \\
\text { Rate }\end{array}$ & $\begin{array}{l}\text { Hyperglycemia } \\
\text { Rate }\end{array}$ & $\begin{array}{l}\text { Hypoglycemia } \\
\text { Rate }\end{array}$ \\
\hline Average glucose monitoring frequency & - & $-0.172 * *$ & $-0.180 * *$ & $0.465^{* *}$ & $-0.147 * *$ & -0.041 \\
\hline Average hospitalization days & $-0.172 * *$ & - & $0.299 * *$ & $-0.287^{* *}$ & 0.030 & 0.096 \\
\hline Average glucose level & $-0.180 * *$ & $0.299 * *$ & - & $-0.324 * *$ & 0.245 & 0.152 \\
\hline Glucose compliance rate & $0.465 * *$ & $-0.287 * *$ & $-0.324 * *$ & - & $-0.199 * *$ & $-0.218 * *$ \\
\hline Hyperglycemia rate & $-0.147 * *$ & 0.030 & $0.245 * *$ & $-0.199 * *$ & - & 0.114 \\
\hline Hypoglycemia rate & -0.041 & 0.096 & $0.152 * *$ & $-0.218 * *$ & $0.114 *$ & - \\
\hline Average fasting glucose level & -0.036 & $0.137^{* *}$ & $0.402 * *$ & -0.045 & -0.092 & -0.057 \\
\hline Average glucose after breakfast & -0.075 & $0.217^{* *}$ & $0.569 * *$ & $-0.254 * *$ & 0.076 & 0.083 \\
\hline Average glucose before lunch & $-0.130 *$ & 0.057 & $0.453^{* *}$ & $-0.190 * *$ & $0.206^{* *}$ & 0.152 \\
\hline Average glucose after lunch & $-0.101 *$ & $0.133^{* *}$ & $0.468^{* *}$ & $-0.324 * *$ & 0.052 & $0.153^{* *}$ \\
\hline Average glucose before dinner & $-0.147 * *$ & $0.107^{*}$ & $0.497 * *$ & $-0.142 * *$ & $0.121 *$ & $0.139 * *$ \\
\hline Average glucose after dinner & $-0.146 * *$ & $0.258^{* *}$ & $0.446 * *$ & $-0.313^{* *}$ & $0.224 * *$ & $0.147^{* *}$ \\
\hline Average bedtime glucose & $-0.176 * *$ & $0.166^{* *}$ & $0.425^{* *}$ & $-0.199 * *$ & $0.149 * *$ & 0.065 \\
\hline Average night glucose & $-0.129 *$ & $0.110 *$ & $0.270^{* *}$ & $-0.110 *$ & 0.067 & 0.014 \\
\hline Average hospitalization hyperglycemia & -0.012 & -0.084 & $0.107^{*}$ & $-0.140 * *$ & $0.187 * *$ & 0.070 \\
\hline Average hospitalization hypoglycemia & $0.121 *$ & -0.069 & -0.044 & $0.163^{* *}$ & $-0.134 * *$ & $-0.099 *$ \\
\hline
\end{tabular}

Notes: $* \mathrm{P}<0.05 ; * * \mathrm{P}<0.01$.

Table 7 Multiple Linear Regression Analysis of the Glucose Compliance Rate

\begin{tabular}{|l|c|c|c|c|c|c|c|}
\hline Variable Quantity & B & S.E. & $\boldsymbol{\beta}$ & $\mathbf{t}$ & \multicolumn{2}{|c|}{$\mathbf{p}$} & \multicolumn{2}{|c|}{ 95\% Confidence Interval } \\
\hline Constant quantity & 80.579 & 9.349 & & 8.619 & 0.000 & 63.633 & 99.903 \\
Average glucose monitoring frequency & 0.459 & 0.051 & 0.391 & 9.088 & 0.000 & 0.356 & 0.556 \\
Average hospitalization days & -1.242 & 0.358 & -0.153 & -3.466 & 0.001 & -2.031 & -0.436 \\
Average glucose level & -2.854 & 0.788 & -0.165 & -3.624 & 0.000 & -4.311 & -1.322 \\
Hyperglycemia rate & -0.129 & 0.071 & -0.079 & -1.818 & 0.070 & -0.284 & 0.025 \\
Hypoglycemia rate & -2.612 & 0.723 & -0.153 & -3.614 & 0.000 & -3.829 & -1.291 \\
\hline
\end{tabular}

Table 8 Multiple Linear Regression Analysis of Average Hospitalization Days

\begin{tabular}{|l|c|c|c|c|c|c|c|}
\hline Variable Quantity & B & S.E. & $\boldsymbol{\beta}$ & $\mathbf{t}$ & \multicolumn{2}{|c|}{$\mathbf{p}$} & \multicolumn{2}{|c|}{ 95\% Confidence Interval } \\
\hline Constant quantity & 8.202 & 1.364 & & 6.015 & 0.000 & 8.394 & 11.238 \\
Average glucose monitoring frequency & -0.007 & 0.008 & -0.048 & -0.895 & 0.371 & -0.023 & 0.009 \\
Average glucose level & 0.515 & 0.109 & 0.242 & 4.735 & 0.000 & 0.270 & 0.744 \\
Glucose compliance rate & -0.024 & 0.007 & -0.197 & -3.466 & 0.001 & -0.042 & -0.008 \\
Hyperglycemia rate & -0.016 & 0.01 & -0.078 & -1.591 & 0.112 & -0.039 & 0.002 \\
Hypoglycemia rate & 0.05 & 0.103 & 0.024 & 0.489 & 0.625 & -0.121 & 0.276 \\
\hline
\end{tabular}

In the present study, a hospital glycemic management system with information integration was actively adopted for patients with malignant tumors and hyperglycemia. The physical and professional space limitations between specialties were overcome using the Internet, and patients from different oncology departments in the hospital were included in the virtual endocrinology ward for patient management so that malignant tumor patients with hyperglycemia did not require transfer to another department for radiotherapy, chemotherapy or surgery. They received professional treatment and monitoring with endocrinology doctors in each department, improving the glycemic management effect during hospitalization. In our study, the hospital glycemic management system with information integration was used and increased the compliance rate of patients in the intervention group compared 
Table 9 Comparison of Patient Satisfaction and Satisfaction Percentage

\begin{tabular}{|l|c|c|c|c|}
\hline Group & $\mathbf{n}$ & Very Satisfied/Percentage (\%) & Satisfied/Percentage (\%) & Not Satisfied/Percentage (\%) \\
\hline Control group & 196 & $105 / 53.57 \%$ & $72 / 36.73 \%$ & $19 / 9.70 \%$ \\
\hline Observation group & 197 & $157 / 79.69 \%$ & $35 / 17.77 \%$ & $5 / 2.54 \%$ \\
\hline$\chi^{2}$ & & & 8.774 & \\
\hline$P$ & & & 0.003 & \\
\hline
\end{tabular}

with that in the control group $(\mathrm{P}<0.05)$. The average glucose levels in the intervention group before and after breakfast, lunch, and dinner, at bedtime, and at night, as well as daily levels, were better than those in the control group $(\mathrm{P}<0.05)$, effectively improving the therapeutic effect of patients with malignant tumors and hyperglycemia. The results were similar to previous study data. ${ }^{17}$ In the intervention group, the average total blood glucose control rate still did not reach the ideal target. On the one hand, this finding may be related to tumor treatment, which is often affected by stress factors such as chemotherapy, radiotherapy and surgery; on the other hand, it may be due to the shorter observation time. However, the average blood glucose level of each period was lower than that of the control group, and the hypoglycemic effect of the intervention group was significantly better than that of the control group, which are exciting findings. Thus, with the continuous update of the information system and mutual cooperation of departments, the average total compliance rate of blood glucose could be further improved.

Additionally, our results revealed that the average daily glucose level and glucose compliance rate in the intervention group were improved, and the incidence of hyperglycemia and hypoglycemia in the intervention group was lower than that in the control group $(\mathrm{P}<0.05)$. Correlation analysis suggested that the improvement in the daily average glucose level and glucose compliance rate was significantly correlated with the reduction in the incidence of hyperglycemia/hypoglycemia. Thus, this system helped to reduce the incidence of high-risk glycemic events, ensure the safety of patients in hospitals, and provide security in terms of the safety of patients with malignant tumors and hyperglycemia. We also found that this system leads endocrinologists to screen abnormal blood glucose more actively in the hospital, comprehensively evaluate the condition and treatment plan, and formulate individualized medication guidance, which promote the transformation of patients' blood glucose management from passive to active intervention. Notably, cooperation between departments has been strengthened to ensure the safety of patients and quality of medical treatment.

Blood glucose monitoring data are important to formulate the treatment plan and to timely adjust the hypoglycemic regimen to reach the glucose target faster. Our results suggest that the hospital glycemic management system with information integration significantly increased the average frequency of blood glucose monitoring in the intervention group compared with that in the control group $(\mathrm{P}<0.05)$, while the compliance rate and multiple indicators of blood glucose were significantly improved compared with that of the control group $(\mathrm{P}<0.05)$. Additionally, regression analysis showed that the frequency of blood glucose monitoring had the strongest correlation with the blood glucose compliance rate, suggesting that increasing the frequency of blood glucose monitoring effectively improved the compliance rate of patients with hyperglycemia. This finding is similar to the results of several studies on patients with diabetes conducted in the endocrinology department. ${ }^{18,19}$ More importantly, our research revealed that the application of this system also increased the attention of non-endocrinology medical staff to blood glucose monitoring and improved the blood glucose control of cancer patients with hyperglycemia, which may play an important role in improving the prognosis of cancer patients. This investigation also revealed that the average number of hospitalization days of patients in the intervention group was significantly lower than that in the control group. Correlation analysis and multiple regression analysis indicated that the frequency of blood glucose monitoring was negatively correlated with the average number of hospitalization days, although it was not a direct independent factor. Additionally, with the increase in the blood glucose frequency, the compliance rate of blood glucose was improved. Although it was negatively 
correlated with the average number of hospitalization days, the compliance rate of blood glucose in patients with malignant tumors and hyperglycemia in nonendocrinology departments led to a reduced average number of hospitalization days. Consequently, the medical burden of patients with malignant tumors and hyperglycemia and improving satisfaction.

In summary, we investigated the glycemic management mode of patients with malignant tumors and hyperglycemia. By establishing the hospital glycemic management system with an information integration and management team led by the endocrinology department, an Internetbased blood glucose management platform was built, and the hospital blood glucose information management process and quality control were implemented to provide professional, real-time and dynamic information for patients with malignant tumors and hyperglycemia. This system can increase the value of endocrinology, enhance the awareness of glycemic management of medical doctors in the tumor department, promote the standardization of the glycemic management process, improve the efficiency of blood glucose management, the rate of blood glucose compliance and quality of life, reduce the occurrence of high-risk blood glucose levels, and shorten the average inhospital time. Thus, this system has high clinical application value.

\section{Limitations}

Our research has some limitations. First, the sample size was small, and the follow-up time was short. Second, the study included only patients recruited from one hospital; thus, a larger multicenter study with long-term follow-up is required.

\section{Data Sharing Statement}

Excel data used to support the findings of this study are available from the corresponding author (email: wqn11@126.com) upon request after the manuscript published 3 months.

\section{Acknowledgments}

This work was supported by grants from the Joint Medical Research Project of Chongqing Science and Technology Bureau and Health Commission (2021 msxm311); Chongqing Science and Technology Bureau and Health Commission of Chinese Medicine Technology Innovation and Application Development Project (2020ZY013540); Research Institute Performance Incentive and Guidance
Project of Chongqing Science and Technology Bureau (cstc2019jxj130006); and Decision Making Consultation and Management Innovation Project of Science and Technology Bureau of Shapingba District (jcd202038). Juan Jiang and Danlan Pu are co-first authors for this study.

\section{Disclosure}

The authors declare no conflicts of interest.

\section{References}

1. Qi J, He P, Yao H, et al. Cancer risk among patients with type 2 diabetes: a real-world study in Shanghai, China. J Diabetes. 2019;11 (11):878-883. doi:10.1111/1753-0407.12926

2. International Diabetes Federation. IDF Diabetes Atlas-8th ed. 2017. Available from: http://www.diabetesatlas.org/. Accessed June 11, 2021.

3. Handelsman Y, Leroith D, Bloomgarden Z, et al. Diabetes and cancer-an AACE/ACE consensus statement[J]. Endocrine Pract. 2013;19(4):675-693.

4. Chen W, Zheng R, Baade PD, et al. Cancer statistics in China, 2015. CA Cancer J Clin. 2016;66(2):115-132.

5. Montemurro N, Perrini P, Rapone B. Clinical risk and overall survival in patients with diabetes mellitus, hyperglycemia and glioblastoma multiforme. A review of the current literature. Int J Environ Res Public Health. 2020;17(22):8501.

6. Paternoster S, Falasca M. The intricate relationship between diabetes, obesity and pancreatic cancer. Biochim Biophys Acta Rev Cancer. 2020;1873(1):188326.

7. Wang C, Wang X, Gong G, et al. Increased risk of hepatocellular carcinoma in patients with diabetes mellitus: a systematic review and meta-analysis of cohort studies. Int $j$ Cancer. 2012;130 (7): 1639-1648.

8. Mandolfo N, Berger A, Hammer M. Glycemic variability in patients with gastrointestinal cancer: an integrative review. Eur J Oncol Nurs. 2020;48:101797.

9. Mallik R, Chowdhury TA. Metformin in cancer. Diabetes Res Clin Pract. 2018;143:409-419.

10. Suh S, Kim KW. Diabetes and cancer: cancer should be screened in routine diabetes assessment. Diabetes Metab J. 2019;43(6):733-743.

11. Polednak AP, Phillips CE. Obtaining data on comorbid diabetes among patients in a U.S.population-based tumor registry. $J$ Registry Manag. 2010;37(2):57-64.

12. Holly JMP, Biernacka K, Perks CM. The Neglected Insulin: IGF-II,a metabolic regulator with implications for diabetes, obesity, and cancer. Cells. 2019;8(10):1207.

13. Hiestand A, Flory J, Chitkara R. Hospitalization as an opportunity to optimize glycemic control in oncology patients. Curr Diab Rep. 2019;19(12):149.

14. American Diabetes Association. 2. Classification and diagnosis of diabetes. Diabetes Care. 2017;40(Suppl 1):S11.

15. Guo XH. Persistent education, behavior modification, lifelong management: the interpretation of life-style intervention of national guidelines for the prevention and control of diabetes in primary care (2018). Zhonghua Nei Ke Za Zhi. 2019;58(8):610-612.

16. Barone BB, Yeh HC, Snyder CF, et al. Long-term all-cause mortality in cancer patients with preexisting diabetes mellitus: a systematic review and meta-analysis. JAMA. 2008;300(23):2754-2764.

17. Vogt AP, Bally L. Perioperative glucose management: current status and future directions. Best Pract Res Clin Anaesthesiol. 2020;34 (2):213-224. 
18. Kim HS, Sun C, Yang SJ, et al. Randomized, open-label, parallel group study to evaluate the effect of internet-based glucose management system on subjects with diabetes in China. Telemed $J$ E Health. 2016;22(8):666-674.
19. Cho JH, Lee HC, Lim DJ, Kwon HS, Yoon KH. Mobile communication using a mobile phone with a glucometer for glucose control in Type 2 patients with diabetes: as effective as an Internet-based glucose monitoring system. $J$ Telemed Telecare. 2009;15(2):77-82.

\section{Publish your work in this journal}

Diabetes, Metabolic Syndrome and Obesity: Targets and Therapy is an international, peer-reviewed open-access journal committed to the rapid publication of the latest laboratory and clinical findings in the fields of diabetes, metabolic syndrome and obesity research. Original research, review, case reports, hypothesis formation, expert opinion and commentaries are all considered for publication. The manuscript management system is completely online and includes a very quick and fair peer-review system, which is all easy to use. Visit $\mathrm{http}: / / \mathrm{www}$.dovepress.com/testimonials.php to read real quotes from published authors. 